\title{
Visibilidade e identidade de São Paulo. Rearranjos figurativo-plásticos na ressignificação dos valores ${ }^{1}$ Visibility and identity of São Paulo. Figurative- plastic rearrangements in the ressignification of the values
}

\author{
Ana Claudia de Oliveira \\ Professora da Pontifícia Universidade Católica de São Paulo, Brasil. Doutora em Comunicação e Semiótica pela Pontifícia \\ Universidade Católica de São Paulo, Brasil. E-mail: anaclaudiamei@hotmail.com
}

\begin{abstract}
Resumo:
A partir do exame do emblema da cidade de São Paulo que, retomando figurativa e plasticamente os valores da fundação colonial, foi adotado no início do século XX e perdura até o contemporâneo, estampado na bandeira do município e também nas laterais dos meios de transporte público, entre outros usos, esse artigo examina um conjunto de slogans e traços emblemáticos, a partir dos quais trata como a visibilidade da megalópole tem sido alicerçada nos valores de liderança, dinamismo, conquista, inovação e modernidade. Concretizados nos vários arranjos figurativoplásticos, esses valores definem como papel temático da cidade o de conduzir o município, o Estado e o País. Esses arranjos figurativo-plásticos exibem uma São Paulo jamais pronta, mas em contínua transformação, portanto, em movimento. Do recente slogan São Paulo, cidade limpa! ao atual São Paulo, cidade linda!, o artigo reflete como a chamada para a estética da beleza de São Paulo mostra discursivamente uma cidade que se prepara para ser acabada seguindo o seu papel temático e reitera uma cidade que se ressignifica a partir dos mesmos valores mostrados em reescritura continuada de preservação de sua dinâmica identitária posta em visibilidade mediática para afetar a população e comprometê-la com o fazer junto São Paulo.
\end{abstract}

\section{Palavras-chave:}

São Paulo; Visibilidade da identidade; Papel Temático; Figurativo-plástico; Reescritura.

\begin{abstract}
:
Adopted in the early $20^{\text {th }}$ century until nowadays, the emblem of the city of São Paulo recaptures figurative and plastically the colonial values of its foundation and it can be found on the flag of the city, on the side structures of the means of public transportation, among other places. From the analysis of this emblem, this article

\footnotetext{
${ }^{1}$ Esse artigo integra o projeto de pesquisa interdisciplinar entre Programas de Pós-Graduações da PUC-SP, com apoio PIPEq, em desenvolvimento nos anos 2016 e 2017, intitulado Territorialidades traçadas pelos fluxos populacionais cotidianos na cidade de São Paulo.
} 
examines a set of slogans and emblematic traces from which we can comprehend how the visibility of the megalopolis has been based on the values of leadership, dynamism, achievement, innovation and modernity. Concretized in the various figurative-plastic arrangements, these values define the thematic role of the city as a conductor of the municipality, the State and the Country. These figurative-plastic arrangements exhibit a never ready São Paulo, in continuous transformation and always moving on. From the recent slogan, São Paulo, a clean city! to the current one, São Paulo, a beautiful city!, this article reflects on how these calling for the aesthetic beauty of São Paulo shows, discursively, a city that prepares itself to be following its the thematic role. Those calling reiterates a resignified town from the same values shown in the ongoing rewriting preservation of its dynamic identity placed into media visibility to affect and the population and compromise it with making São Paulo together.

\section{Keywords:}

São Paulo; Identity visibility's; Thematic role; Plastic-figurative; Rewritings.

\section{Os valores na construção identitária}

As administrações públicas de São Paulo montam as suas plataformas axiológicas por meio de emblemas e slogans distintos que põem em circulação seus valores. Ao mesmo tempo em que esses a distinguem da construção identitária de outras urbes, eles também a diferenciam da própria imagem da cidade de gestão em gestão. Nessa dinâmica de visibilidade identitária destacam-se as reiterações isotópicas e a montagem coesa de escolhas temático-figurativo-plásticas que configuram os modos de presença de São Paulo.

Que modos de presença são esses? Como uma cidade organiza-se para ser um destinador forte de si? Qual a eficácia dessa visibilidade identitária? Como ela afeta a população? O objetivo desse artigo é, pois, responder essas questões tomando como matriz a análise da expressão latina "Non Ducor Duco"2, que está no brasão da cidade ainda hoje estampando o Poder Público municipal no horizonte paulistano. Como essa faz ver no contemporâneo uma invariabilidade nos valores da São Paulo

\footnotetext{
${ }^{2}$ Para maior detalhamento sobre essa análise consultar: OLIVEIRA, Ana Claudia. De um emblema colonial a uma marca turística de São Paulo: um universo identitário de partilha e pertencimento. In OLIVEIRA, Ana Claudia de (Org.). São Paulo e Roma Práticas de vida e sentido. São Paulo, Estação das Letras e Cores-CPS Editores, 2017, p. 75-93.
}

INTERIN, v. 23, n. 1, jan./jun. 2018. ISSN: 1980-5276. 
de Piratininga desde a sua fundação pelos colonizadores portugueses? Como é operada essa permanência axiológica?

Figura 1: Desde o ano 1917, o brasão da cidade de São Paulo é o símbolo da cidade, capital do Estado de São Paulo e maior capital do Brasil. O governo ditatorial de Getúlio Vargas, em 1937, suprimiu por decreto, todos os emblemas dos Estados e Cidades pelos nacionais e esses símbolos só voltaram a ter seus usos autorizados em 1946 com a Nova Constituição. São Paulo recolocou seu brasão em uso.

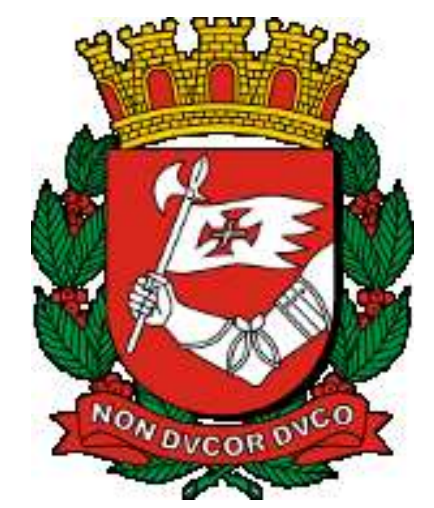

Fonte: ww1.prefeitura.sp.gov.br

O escudo tem a cor vermelha como fundo similar à terra vermelha fértil em que se plantam as ações de audácia e coragem, ao mesmo tempo que esse cromatismo enfatiza o estar em ação. Sobre esse cenário cromático posiciona-se a figuratividade central de um braço destro armado, que se move do flanco esquerdo e empunha uma bandeira de quatro pontas farpadas. Na centralidade dessa no ângulo da flexão do braço e antebraço tem-se a cruz da Ordem de Cristo também em vermelho o que retoma a participação jesuítica na criação da cidade que levou o nome de São Paulo, um dos maiores propagadores do cristianismo. Por ela ter cravado no vermelho, um centro no qual um tracejado branco-prata corta em linha vertical a linha horizontal em ângulo reto, há um reiterar do fazer de conquista tanto da fé como de novos territórios enlaçando esses atos expansionistas. Içado em haste, ela é lanceada em acha com cromatismo branco-prata. Na parte superior do escudo está posicionada a coroa mural de ouro de oito torres, com as suas portas abertas de goles que permitem visualizar o mesmo fundo vermelho. As laterais do escudo são cercadas de dois ramos de folhas de cafeeiro com frutos que se entrecruzam na centralidade inferior. A riqueza agrícola do Estado de São Paulo na primeira metade do século XX, os ramos de café volteiam o escudo e, na base, um listel vermelho estampa na horizontal a divisa "NON DUCOR DUCO".

INTERIN, v. 23, n. 1, jan./jun. 2018. ISSN: 1980-5276. 
Adotado pela municipalidade em 1917, esse símbolo completou cem anos. Ele atesta uma constância em seu perdurar que nos leva a pensar na sedimentação consolidada de valores de luta, conquista, dominação e culto de riquezas do café à industrialização e aos serviços, e culto expansionista da evangelização bastante similar aos valores mercantilistas de expansão territorial da coroa portuguesa no século XVI que se firmaram nos séculos vindouros e perduram ainda no século XXI. Mesmo se esse emblema permaneceu em circulação ao longo do século XX ele também foi complementado por outros símbolos e slogans que funcionam em relação de solidariedade entre si e, na medida em que lhe dão reforço, pode-se dizer que esses inserem um grão de inovação que, por minimal que seja, não é imperceptível e passa a ser apreendido no seu fazer sentido. Os valores instalados nas novas plásticas em rearranjos figurativos já consolidados têm então importantíssimo papel de reiteração axiológica.

A definição de A.J. Greimas sobre o conceito de figuratividade é para nós central para entendermos como é a partir dela que se pode entender como os semantismos do figurativo, concretizados pelas escolhas plástico-rítmicas que os traduzem em linguagens, reatualizam os valores assumidos no sentido das ações e atitudes de um télos condutor de São Paulo. Vamos nos centrar na conceituação tirando as repercussões para o nosso estudo. Para Greimas figuratividade:

não é uma simples ornamentação das coisas, ela é esta tela do parecer cuja virtude consiste em entreabrir, em deixar entrever, graças ou por causa de sua imperfeição, como que uma possibilidade de além (do) sentido. (GREIMAS, 2017, p. 82).

Somos levados a entrever que essa tela do parecer centenária do emblema entreabre o seu sentido com força de reatualizar-se a cada tremular do braço, no seu fincar no solo a bandeira do município, ou estampá-la nas laterais dos ônibus para ser entrevista em trânsito pelas vias da urbe e lembrar ao que a vê a orientação conquistadora da cidade que lhe é assim atualizada com o propósito de reafirmar seus valores. Os modos como os mundos das linguagens sincréticas traduzem os mundos axiológicos do social estão, pois, a serviço da construção de visibilidade da identidade, que resiste até a atualidade e define a megalópole não ser conduzida, mas

INTERIN, v. 23, n. 1, jan./jun. 2018. ISSN: 1980-5276. 
conduzir com possibilidades de além (do) sentido, que nos levam à atualização da conclusão propositiva greimasiana: "os humores do sujeito reencontram, então, a imanência do sensível" (GREIMAS, 2017, p. 82). Um sensível é vivificado a partir da plasticidade do emblema que atualiza a cada relance a entrevisão do dinamismo ascensional da marcha conquistadora branco-prata sempre avançando, no cromatismo vitalista do vermelho no seu contraste com o branco-prata e a produção de riquezas das explorações como os frutos do café particularizam.

Esse reencontro com o sensível não é sem consequência pois nas variações dos arranjos plástico-rítmicos dessa figuratividade opera-se o fazer sentir a dinamicidade dessa São Paulo sempre se construindo que propomos analisar ancorados na semiótica de A.J. Greimas e nos desenvolvimentos dessa na sociossemiótica de E. Landowski e na semiótica plástica de J.-M. Floch, conceituações dessas vertentes que nós mesmos temos complementado e aprofundado em uma semiótica das práticas de vida urbana nos objetos estudados pelo Centro de Pesquisas Sociossemióticas - CPS. Com esses fundamentos abordamos as dinâmicas da construção da visibilidade identitária na pulsação da cidade e como é essa que faz viver e sentir o que experimentam seus valores.

\section{As figuratividades da primeira metade do século $X X$}

No início do século XX, outras denominações afirmavam-se como qualificantes da São Paulo de então: "São Paulo da garoa" e de uma "São Paulo dos lampiões a gás". O primeiro indicava uma máxima característica das condições climáticas enquanto o segundo referia-se ao estágio de urbanização da metrópole.

Se a São Paulo da garoa teve seu clima alterado, a São Paulo da iluminação por lampiões a gás iniciou-se em 1927, quando a Companhia de energia inglesa, a Light, fechou um contrato para modernizar a iluminação pública que até então faziase com óleo de mamona, baleia ou lampiões a gás. Os postes em ferro fundido com figuratividades do brasão de armas da república brasileira, ou simplesmente com flores em ferro são cada vez mais raros de ser encontrados em todo o esplendor de sua altivez, mas ao se deparar com um desses, experimenta-se como essas peças 


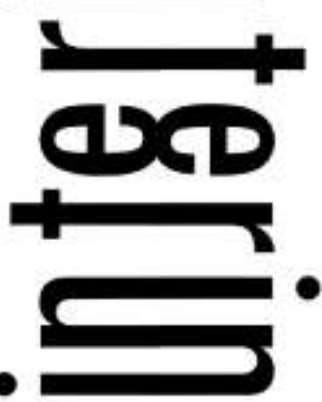

vivificam uma São Paulo da década de 30, que continua a existir o que os confirma como um dos símbolos de sua transformação urbana.

Figuras 2, 3 e 4: Os antigos primeiros postes foram modernizados com os postes em ferro fundido da iluminação a gás de São Paulo.
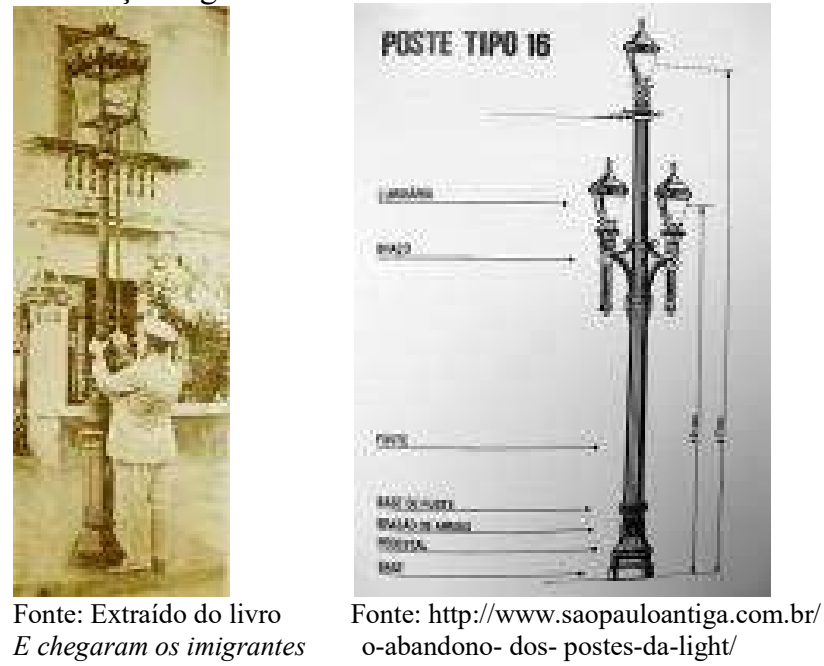

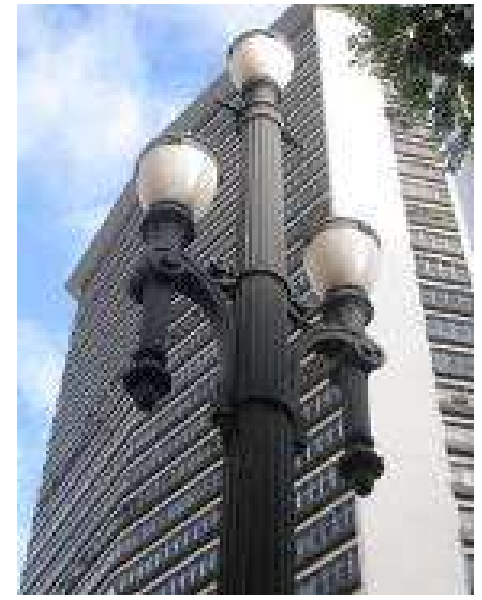

Fonte: Fotografia de Sidnei Lugounov. Edição Postes Históricos: lugouv.blogspot.com

Figura 5, 6 e 7: Na atualidade, os postes memória de então estão sem manutenção dando visibilidade ao pouco cuidado destinado pelo poder público ao patrimônio urbano que, entre outras consequências, difunde um não valor assumido da preservação histórica.

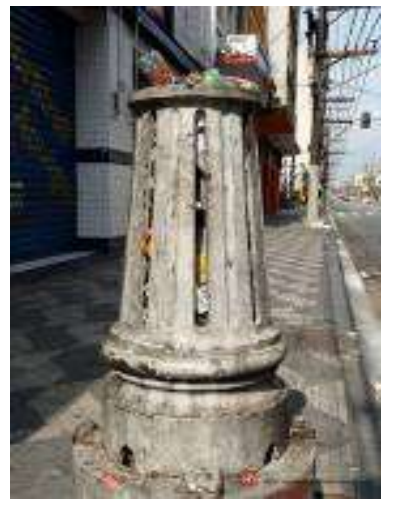

Fonte:

http://www.saopauloantiga.com. br/ o-abandono-dos-postes-dalight/

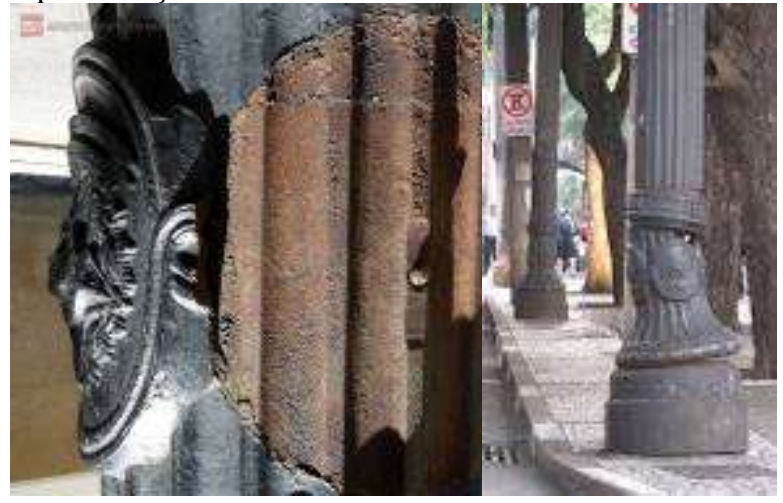

Fonte:

http://www.saopauloantiga.com.br

/ o-abandono-dos-postes-da-light/
Fotografia Douglas Nascimento

Fonte:

http://www.saopauloantiga.com.br/oabandono-dos-postes-da-light/

Em continuidade, a iluminação trilhou uma linha ininterrupta de mutações até à atual de lâmpadas leds que domina na Avenida Paulista, no Parque do Ibirapuera, entre outras localidades. A iluminação dá visibilidade a uma cidade que insere no seu desempenho as mais novas tecnologias de modo a qualificar-se como cidade inteligente. 
Figuras 8 e 9: Dois ângulos da iluminação da Avenida Paulista após a troca para as novas lâmpadas e postes de LED da Philips de $113 \mathrm{~W}$. A AES Eletropaulo é a empresa responsável pela distribuição de energia e junto com o Ilume (Departamento de Iluminação Pública), órgão da prefeitura, assumiram os custos que atingiu a soma de $\mathrm{R} \$ 11$ milhões.

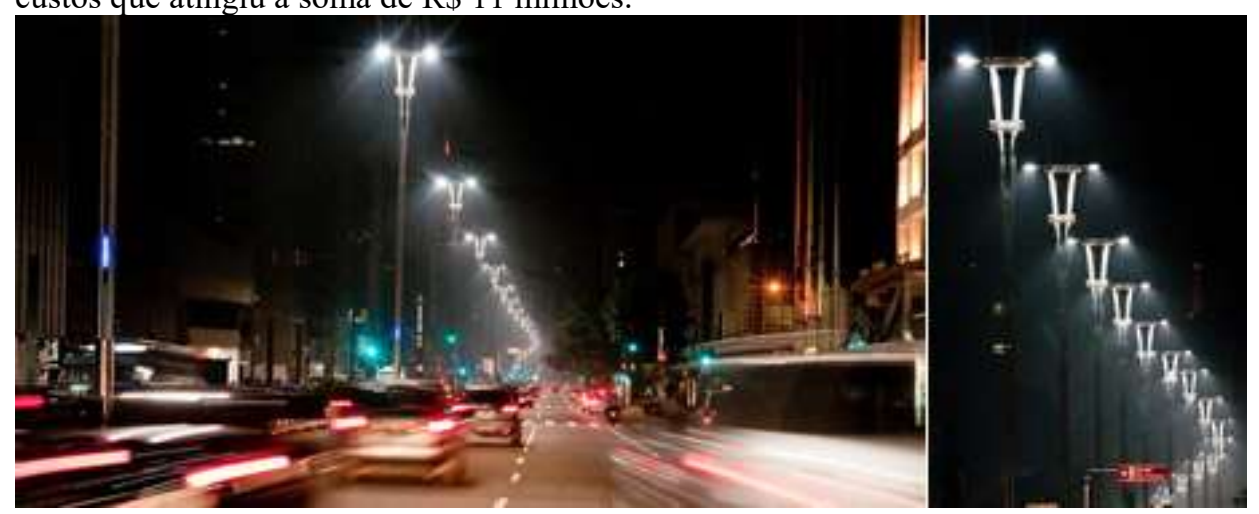

Fonte: Fotografias de Julia Chequer/R7

Na sequência da São Paulo da industrialização que conduz a cidade para a segunda metade do século, até a cidade dos serviços que assume ser hoje, os ditames publicitários vão propagar uma metrópole centrada no seu crescimento e modernização. Alguns desses novos lemas são: "São Paulo, a locomotiva do Brasil"; "São Paulo não pode parar"; "São Paulo (é) a cidade que mais cresce no mundo", que alargam a visibilidade do percurso identitário da urbe como aquela que jamais se imobiliza e faz do transformar-se a sua imagem. Por sua vez "São Paulo, a locomotiva do Brasil" fazia ver o papel da metrópole na narrativa do Brasil, a parte em relação ao todo do país que já pode ser considerado um dar visibilidade às competências modais da cidade a partir da exaltação do seu grau de desenvolvimento tecnológico, assim como reconhece-se a consistência estésica do emblema e slogans para fazer sentir o seu vitalismo.

Esse caráter transformador ininterrupto é, mais uma vez, reiterado, quando a São Paulo de agora elege, como sua voz de comando, o aumento de sua aceleração, em um momento em que, por todos os cantos, é propagada a diminuição de velocidade adotada na gestão de Fernando Haddad, entre outras razões, como nas demais cidades globais, para melhor fluir o trânsito e abaixar os índices de acidentes. Com "Acelera São Paulo", uma aparente contradição de João Dória que assusta ao mesmo tempo em que nos põe a refletir se estaria ele referindo-se unicamente à caoticidade do tráfego paulistano. A ênfase nas competências modais de São Paulo e nas competências estésicas de seus símbolos mantem uma coesão fazendo ver e sentir o seu papel temático. 


\section{Dinâmica identitária de São Paulo: De cidade limpa, à cidade graffitada, à cidade linda}

Ações dos recentes dirigentes da municipalidade fizeram São Paulo passar, primeiro, por uma higienização de sua visualidade abarrotada de publicidade, com o comando da chamada "São Paulo cidade limpa" (Gilberto Kassab: 2006-2012). Essa foi sucedida por uma gestão que fez São Paulo ocupar mais o seu espaço público com a população dele desfrutando o que se deu em concomitância com a explosão de graffitis por todos os seus pontos cardinais (Fernando Haddad: 2013-2016) e conduziu a cidade para uma direção mais socializante do bem comum. Finalmente, numa retomada direta da cidade limpa entrar na era da "São Paulo cidade linda" (João Dória: 2017-2020). O que esses lemas atualizam da diretiva que o emblema traçava como percurso narrativo de São Paulo? Explorando a construção identitária da visibilidade oficial da megalópole e o que essa mostra, observou-se que nas ressemantizações continuadas do simulacro do destinador cidade que esse mantém-se no auto comando de sua rota ascensional. Mudam-se os seus meios, mas não os seus fins; e a dianteira de São Paulo no cenário das urbes brasileiras mantém-se.

São Paulo ratifica que continuadamente se diferencia de si mesma para produzir efeitos de sentido de ter sempre novidades que as qualifica como atual. Se no início do século XX tratava-se de uma São Paulo da garoa, dos lampiões a gás e de locomotiva do Brasil; essas fixaram uma São Paulo da atualidade que se fez e se faz renovando-se a exemplo da passagem da iluminação dos lampiões a gás, dos postes de ferro à iluminação a $l e d^{3}$ e que igualmente se prepara para a necessária transformação de sua mobilidade que ainda são obras em construção.

Na sequência desses slogans, os ditames publicitários continuaram a propalar "São Paulo não pode parar"; "São Paulo, a cidade que mais cresce no mundo". Os valores investidos incidem na continuidade do crescimento e da renovação que mantém o seu papel temático.

\footnotetext{
${ }^{3}$ Em outro artigo São Paulo, nos percursos de uma inteligência sensível?, dediquei-me a essa análise Cf. SANTAELLA, Lúcia (Org.). Cidades inteligentes. Para quem? Para que? 1 ed., São Paulo, Ed. Estação das Letras e Cores, v. 1, 2016. p. 146-175.
} 
Com esse ressignificar de valores, a cidade vai ser mais uma vez instigada na segunda década do século XXI, ao ser conclamada por Dória a redinamizar o seu ritmo, agora, ao máximo, acelerando para dar uma arrancada do estágio no qual se encontrava. A ênfase na aceleração não é um valor novo à cidade, ao contrário, é uma ressemantização da cidade que "tem pressa" e "que não pode parar". O comando é, pois, para a cidade dar uma nova alavancada na sua trajetória e manter a intensidade de seu ritmo para promover a diminuição do tempo das mudanças conclamadas como necessárias. "Acelera São Paulo" para tornar possível mudanças já nessa gestão que envolvem uma ação de desburocratização das decisões para ter agilidade, ao mesmo tempo que um processo amplo de discussão pois não são sem consequências o número de acordos com a iniciativa privada para gerir vários setores e organismos públicos que consomem as reservas municipais.

Assim as competências modais de São Paulo têm garantido um desempenho coerente da força de comando de sua própria bandeira que dita sua conduta. "Acelera São Paulo" pode então ser tomado como imperativo para a cidade recuperar o que perdeu nas outras gestões ou ao menos o que não ganhou, o que já é uma diferenciação entre a gestão de Dória e as de Haddad e Kassab.

Essas mudanças figurativas de superfície estão a serviço da narratividade que visa a manutenção do papel temático de liderança. Mas as ações dos recentes slogans de uma São Paulo cidade limpa a uma São Paulo cidade linda o que atualizam da diretiva do percurso narrativo? Explorando a construção identitária da visibilidade oficial de São Paulo e o que ela mostra, vamos continuar analisando a atualização continuada da imagem da metrópole na sua pulsação e como essa faz viver os que a habitam injetando estimulação nos modos de estar em uma cidade que apraz e, também, quer tornar-se aprazível.

\section{Limpa e regulada, graffitada e socializada, acelerada e linda, a mesma ou distinta São Paulo?}

A São Paulo da era de Kassab passou por uma higienização radical de sua visualidade $^{4}$. Sem outdoors nas ruas, sem publicidade externa dando visibilidade ao

\footnotetext{
${ }^{4}$ Cf. OLIVEIRA, Ana Claudia de. Fotografia de fotopublicidade na ambientação urbana de São Paulo. INTERIN, v. 23, n. 1, jan./jun. 2018. ISSN: 1980-5276. 
ponto de venda, com limpeza das fachadas, a cidade voltou a mostrar as suas paredes, muros, fachadas, enfim, a arquitetura dos imóveis a partir da Lei $n^{\circ} 14.223$, e do decreto regulamentador $n^{0} 47.950$. A paisagem da pauliceia apresentou então mudanças significativas de aparente neutralização do consumo que ela anima. Ao mesmo tempo em que descortinava a arquitetura, patrimônio histórico, urbanismo, as práticas de vida da população ocuparam mais os espaços públicos também liberados do ocultamento da publicidade de marcas e produtos. Essa conquista carregou uma intencionalidade outra que só foi aparecendo na gestão seguinte na qual as zonas públicas demarcadas passaram com o controle da prefeitura a ser comercializada para fins publicitários sob contínua supervisão e controle da operação. O processo de regulação serviu, portanto, para a captação de verbas para os cofres da municipalidade uma vez que a publicidade regulada canalizou recursos para os cofres públicos. Nos lócus de visibilidade dos novos retângulos dos relógios (administrados pela JC Decaux desde a concorrência de 2012) e nos pontos de ônibus (que a Otima é responsável pela exploração), vimos já na gestão de Haddad as verbas publicitárias crescerem em circular e na gestão de Dória outros locais como os dos mobiliários públicos têm sido estudados para ser negociados. No entanto, a população tem reagido negativamente uma vez que aprendeu a desfrutar da liberação da massiva exposição publicitária e consumista do meio que a rodeia.

Atuando sobre os estados d'alma e de ânimo, essa paisagem promove passagens nos humores dos viventes. Com as mutações São Paulo e sua população aumentaram a sua consciência do direito à qualidade de visibilidade. A Lei Cidade Limpa significou a valorização do bem comum e esse aprendizado não pode já ser revertido como se não tivesse produzido novos sentidos na vida individual e coletiva, na vida privada e pública. A limpeza foi um astuto estratagema que regulou os lugares de publicidade e precificou-os visando o município ter controle financeiro. $\mathrm{Na}$ gestão de Haddad a fiscalização dos infratores da Cidade Limpa continuou rigorosa apesar de menos alardeada. $\mathrm{Na}$ gestão de Doria, há propostas de flexibilização e concessão da Lei para estender as áreas de publicidade para parques, ciclovias, cemitérios públicos, Estádio do Pacaembu, entre outras localidades, assim

In Revista Significação. n. 35. São Paulo, 2011, p. 131-151.

INTERIN, v. 23, n. 1, jan./jun. 2018. ISSN: 1980-5276.

Ana Claudia de Oliveira. Visibilidade e identidade de São Paulo. Rearranjos figurativo-plásticos na ressignificação dos valores. p. 146-166. 
como ser mantida nos luminosos, painéis eletrônicos e suportes digitais. Igualmente as criações do mobiliário urbano pela SP Desenvolvimento Urbano como abrigo para parada de taxi, bebedouro, lixeira, sanitário público, seriam lugares cenários para uma administração da publicidade como nova fonte de verbas.

Esse processo de controle caminha ao lado da regulação de outras manifestações visuais da cidade como a pixação que são alardeadas como enfeitando a cidade. Talvez a mais ruidosa reação da operação de limpeza da "cidade cinza" iniciada com Kassab tenha desdobramentos mais ofensivos na gestão de Dória. $\mathrm{O}$ poder público atual assumiu frontal combate a pixação que teve início após a explosão dessa manifestação parietal que se alastrou por São Paulo de suas periferias aos seus centros num fluxo cujo direcionamento não deixa de ser significante. Se o apagamento dos graffiti é processado por delegados da própria prefeitura que os recobrem com pinturas de cor cinza como será o recobrir a verticalidade dos prédios pixados?

O radicalismo de posicionamentos contraditórios das gestões municipais não deixa de se exponenciar. Do multicolorido com o qual a população foi estabelecendo contato e gosto, ao monocromatismo desvitalizado que levou a população a tomar partido e posicionar-se a favor da São Paulo galeria de graffiti, eis a repercussão com visibilidade mediática que tanto impacta patemicamente a cidade e a população ${ }^{5}$.

\footnotetext{
${ }^{5}$ Essa ação foi analisada no bojo do projeto de pesquisa coletiva na modalidade projeto temático: "Práticas de vida e produção de sentido de São Paulo. Regime de visibilidade, regime de interação, regime de reescritura". Projeto Temático "Práticas de vida e produção de sentido". Cf. CHEN, Luciana et al. "Sentidos da visualidade urbana: o grafite nos Arcos do Bixiga". In: OLIVEIRA, Ana Claudia de (Org.). Sentido e interação nas práticas: comunicação, consumo, educação e urbanidade. São Paulo: Estação da Letras e Cores, 2016, p. 378-379; CHEN, Luciana et al. "As escapatórias nas narrativas urbanas: Arcos do Bixiga como espaço de encenação de polêmicas". In: Anais - Colóquio Internacional Greimas: Desenvolvimentos, apropriações e desdobramentos para uma semiótica das práticas. São Paulo, PUC-SP, 2017, p. 751-767.
} 
Figura 10: Arcos dos italianos ou Arcos do Bixiga, patrimônio histórico de São Paulo, com a ação do graffiti autorizado pela gestão Haddad em 2016.

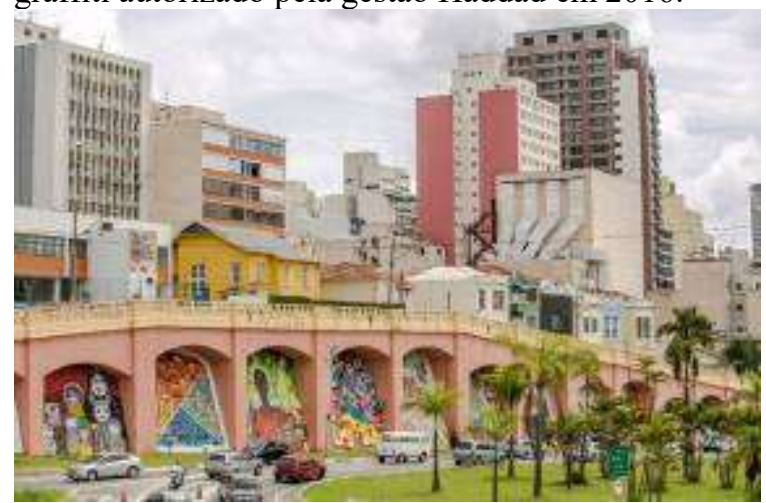

Fonte:https://www.google.com.br/search?q=Arco+dos+italianos+grafitados + em $+\mathrm{S} \% \mathrm{C} 3 \% \mathrm{~A} 3 \mathrm{o}+\mathrm{PAulo}$ $\&$ source $=\operatorname{lnms} \&$ tbm $=$ isch\&sa $=X \& v e d=0$ ahUKEwibio2rgL3WAhVG6CYKHXhiCLkQ_AUICigB\&b iw=1280\&bih=679\#imgdii=sovs3nGq1dL7LM:\&imgrc=d-ACUGqFQKJelM

Figura 11: O estado de apagamento do graffiti dos Arcos do Bixiga e a restauração cromática que, para ser mantida, é na atualidade protegida vinte e quatro horas por dia.

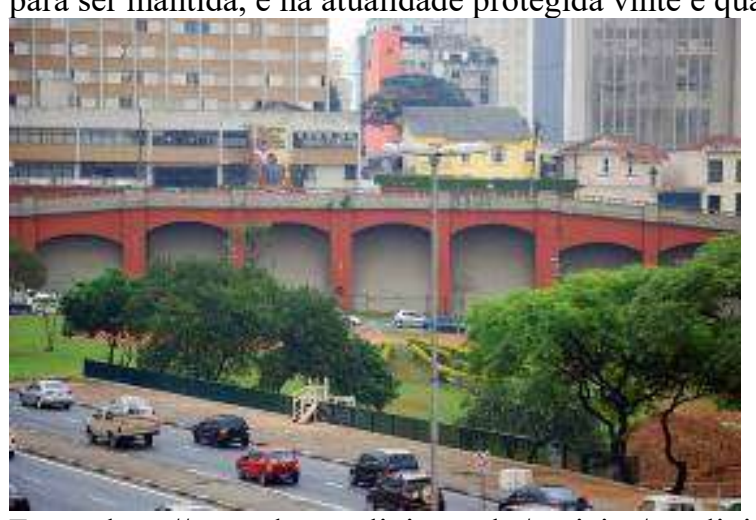

Fonte: http://vereadornatalini.com.br/noticias/natalini-entra-com-acao-popular-contra-grafite-nosarcos-do-bixiga/

Com essa ação, as periferias, zonas em que graffiti, pixação e pixo dão coberturas às casas sem reboco, inacabadas, passou a figurar por todas as centralidades da urbe. Reconhecidos artistas participaram ao lado de artistas pouco conhecidos. Outro tipo de excessivo visual tomou conta da visibilidade de São Paulo e, hoje, o poder público quer manter os graffiti e eliminar pixação e pixo. O fluxo oposto das periferias ao centro antigo, os centros expandidos, com pixação e, principalmente, pixo, unificam a cidade heterogênea e desigual. São inscrições dos trabalhadores habitantes das periferias, cidade dormitório que estão aí manifestas. Em escrituras caligráficas São Paulo está inteiramente pichada com tinta em spray aerossol dificilmente removível, ou por rolo de tinta de cromatismo preto das formas gráficas anguladas e estendidas nas verticais das topologias dos espaços parietais 
vazios nos quais desafiadoramente registram discursos de comando, reinvindicações dessa população que quer ser vista e assegurar o direito de ser considerada em suas necessidades de acesso à vida pública, mobilidade, escola, saúde, lazer, necessidades de expressão para ser.

A posição combativa de Dória gerou além de repercussão mediática um acirramento das relações com os distintos autores. Enquanto com os grafiteiros renomados o apagamento de suas manifestações garantiu a negociação de uma área exclusiva para alocação de uma galeria do graffiti, com os pixadores a guerra foi declarada com todas as armas. Classificados com semantismos disfóricos, a operação Cidade linda armou franco combate da zeladoria visando o seu apagamento. Porém São Paulo resiste mais pichada do que nunca.

Figura 12: Edifício San Vito, na Baixada do Glicério, zona cerealista de São Paulo, é um marco na história da pixação. O imóvel inteiramente degradado na sua verticalidade de vinte e sete andares situava-se na avenida do Estado, número 3 170, tinha sido edificado em 1959. Obra modernista dos arquitetos Kogan \& Zarzur tinha 600 quitintes. Contava com o andar térreo e sobreloja destinados a uso comercial. Na cobertura do imóvel havia um auditório para shows, que também funcionava como mirante da cidade. O pixo nele encontrou a sua matéria primeira de degradação imobiliária e sobre ela o grafismo reiterou o seu discurso contra especulação imobiliária, falta de moradia populares nas centralidades e de direitos de qualidade de vida para toda população.

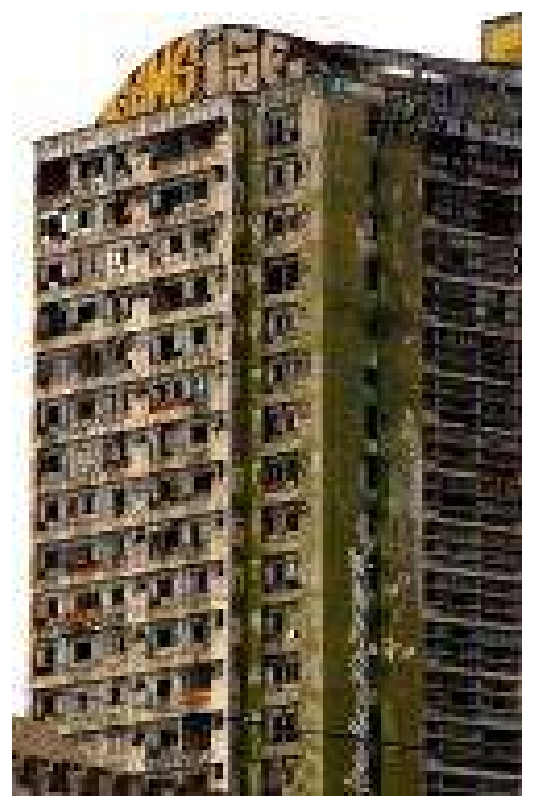

Fonte: https://br.pinterest.com/pin/526428643926980508/

A atual panorâmica de São Paulo pode ser complementada por vistas que não deixam de impressionar o que circula pelas várias centralidades e que não pode não sentir esse clamor que o rodeia em 360 graus.

INTERIN, v. 23, n. 1, jan./jun. 2018. ISSN: 1980-5276. 
Figura 13: Duas panorâmicas do pixo em São Paulo, sendo que na segunda mostra-se também o risco de vida do ato de pixar ao mesmo tempo que assinala a aventura que impulsiona os pixadores na escolha de lugares para provar os seus valores de paulistanos que, com a sua força viva, fincam a bandeira de sua luta para ser vista como emblema de suas condições de vida. Reconfigurações dos valores do município, o pixo ganha visibilidade como reescritura de sua bandeira e emblema que inova na articulação dos mesmos valores.

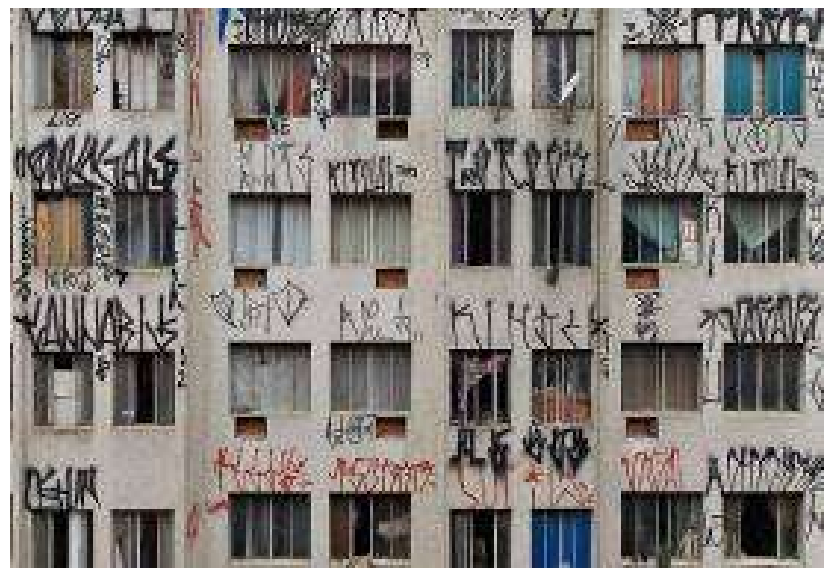

Fonte: http://www.hypeness.com.br/ 2016/02/esse-pixo-atropelou-um-graffitee-o-resultadodividiu-opinioesquem-mesmo-define-o-que-e-arte/

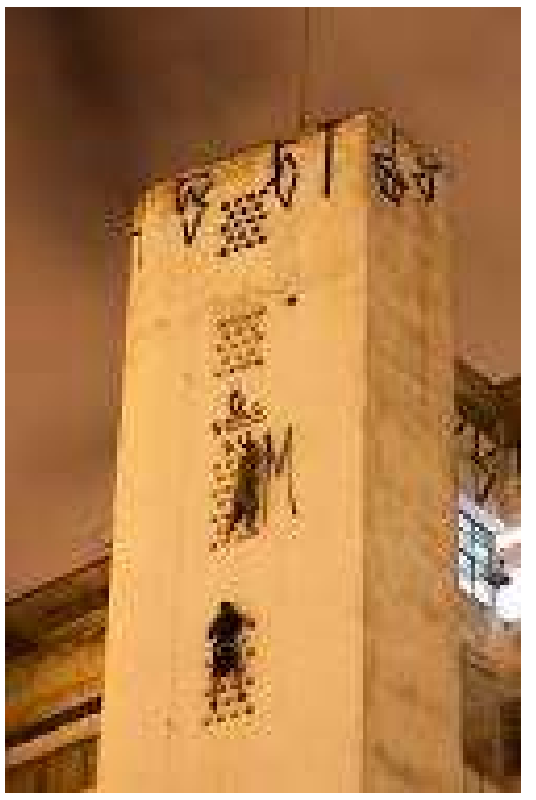

Fonte: http://www.allcityblog.fr/55665pixadores-making-mark/

\section{São Paulo cidade linda}

Entre os significados do adjetivo Linda figuram os de algo excessivamente bonito; que é bom de se ouvir e/ou ver. Uma organização discursiva regida por um ponto de vista tanto ético quanto estético que a seleção semiótica estruturante dos arranjos vai configurar enquanto vista do mundo. Com a competência de produzir efeitos de sentido do que é lindo, no geral, domina uma concepção de beleza que se marca por regras clássicas da harmonia e da simetria. Daí o semantismo de linda ser às vezes equiparado ao de belo e daquilo que agrada ou apraz um sujeito.

Considerando que São Paulo é caracteristicamente desarmônica na sua justaposição de partes dispares e distintas que se ladeiam formando a sua totalidade de sentido, extraímos de suas leis de composição o nosso modo de semiotizar o sentido de linda dessa megalópole a fim de explicitar como ela torna-se vista, 
observada, contemplada e admirada ou rigorosamente analisada, como é o nosso caso, pelos impactos que nos acarreta.

"São Paulo Cidade Linda" foi, já no primeiro dia de mandato em 2 de janeiro de 2017, acompanhado de uma declaração de Dória: "Este é um trabalho amplo de manutenção da cidade. Queremos fazer da cidade de São Paulo um local mais agradável para se viver e para se frequentar". É a escolha mesma do vocábulo "manutenção" que nos permite destacar que esse destinador se apoia em que São Paulo, na sua composição urbanística e arquitetônica, é uma cidade bela; e que a gestão vai tomar medidas por meio de várias equipes de "zeladoria" para essa beleza ser cuidada e tornar assim a cidade mais aprazível ao gosto dos habitantes que poderão dela desfrutar.

Arrisco a dizer que domina uma intencionalidade nessa zeladoria que tende a dar visibilidade a somente um dos lados da São Paulo partida ao meio: partida na beleza de ser linda e na beleza de ser feia. Não é difícil pelo slogan depreender que Dória elegeu a metade da beleza. Na justaposição desses dois vetores, São Paulo configura-se pela diversidade ${ }^{6}$ que domina a sua configuração por efeitos de sentido de gritantes contrastes que nos sensibilizam a senti-la como a do braço erguido empunhando a bandeira tremulante da conquista elevada em um fazer fazer da cidade e dos paulistanos que faz ser São Paulo.

O programa de zeladoria agrupa vários destinadores pertencentes ao poder público, à iniciativa privada, às ONGs e aos cidadãos para juntos, sob a coordenação das Prefeituras Regionais, realizar em regiões da cidade serviços de limpeza e conserto de várias ordens como o quadro da visibilidade.

\footnotetext{
${ }^{6}$ Cf. OLIVEIRA, Ana Claudia de. Avenida Paulista: reminiscências e reescrituras de uma São Paulo inacabada. In: OLIVEIRA, Ana Claudia de (Org.),(2017) São Paulo e Roma Práticas de vida e sentido. Op. cit., p. 415- 436.
}

INTERIN, v. 23, n. 1, jan./jun. 2018. ISSN: 1980-5276. 
Figura 14: Quadro das ações do Programa de manutenção de SP Cidade Linda da Prefeitura de João Dória.
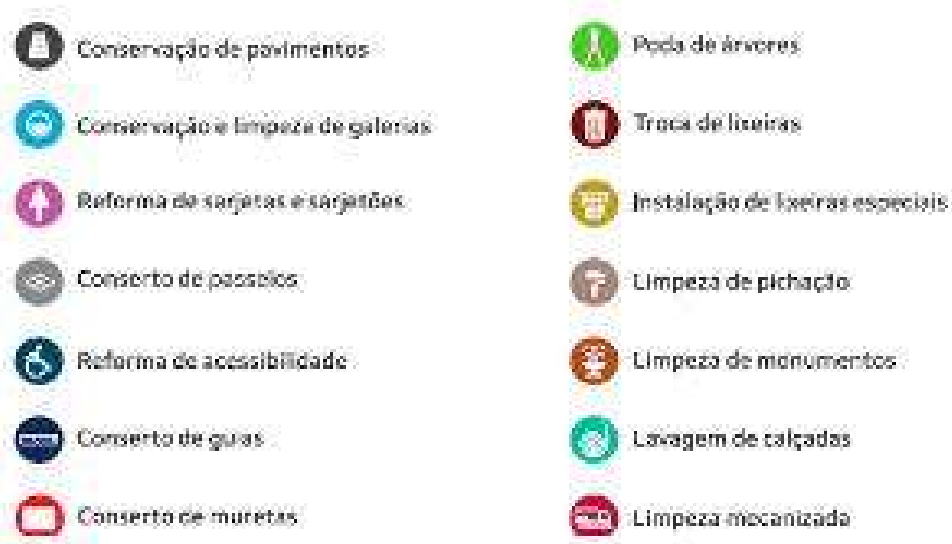

Fonte: Site da Prefeitura de São Paulo

Para essa convocação de atuação conjunta periódica, um cronograma de localidades foi divulgado tendo seu início na Avenida 9 de Julho, no dia 4 de janeiro de 2017, ação que contou com 1.291 pessoas para executar os trabalhos e com a utilização de 176 equipamentos, entre caminhões, varredeiras mecânicas e triciclos.

Figura 15: Várias ações do mutirão de manutenção da Avenida 9 de Julho como retificação da sinalética, lavagem de calçada, poda de árvores, limpeza de pichações, entre outras. O logo da campanha permanece fixado no poste de iluminação com o ensinamento de que lixo se deposita no lixo para a cidade continuar limpa que é um dos atributos para São Paulo ser linda. Limpa e linda são então conectadas e operam em sintonia.
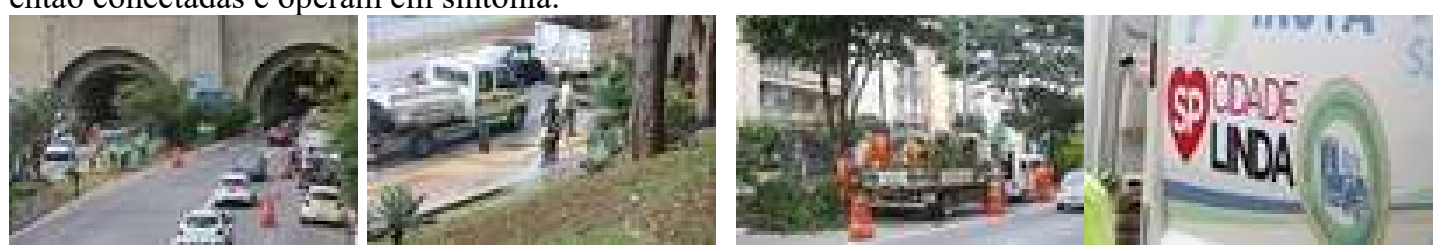

Fonte: http://www.capital.sp.gov.br/noticia/prefeito-participa-da-primeira-acao-do-programa-saopaulo-cidade-linda-1/

No calendário estão ainda indicadas para o mês de janeiro as seguintes intervenções: 7 e 8 na Avenida Paulista; 14 e 15 na Avenida 23 de Maio; 21 e 22 na Avenida Santo Amaro e 28 e 29 na Avenida Tiradentes, e a promessa com a agenda mês a mês do ano de atravessar a cidade. A seleção de avenidas exponenciais mostra que essa é uma ação do município para obter visibilidade junto à própria população e dar assim destaque ao projeto de gestão por meio da cobertura mediática e das redes sociais. A visibilidade mediática é imperativa no fazer ser vista a zeladoria e 
convencer o que vê de sua comprometida com o município. Com esse tipo de chamamento a população toma contato com as ações, tem despertada a sua curiosidade e ativados os seus interesses para integrar a ação que o site da Prefeitura veicula o programa e as várias media o propagam a cada novo ato, comentando, discutindo e avaliando. Pautada nas agendas, a zeladoria apregoada quer que as ações não possam não ser vistas a fim delas garantirem a adesão da população numa trama de envolvimento que faz sentido no tocá-las corpo a corpo.

O logo da ação coloca as iniciais da cidade SP, na cor branca, em uma inclinação dinâmica que é situada no seio de um coração vermelho também inclinado à direita, marcando a sua mobilidade. Em duas linhas, são distribuídas a qualificação: em vermelho e com o uso de tipo gráfico sem serifa, na lateral direita a palavra CIDADE e, abaixo dessa em negrito e também sem serifa, na cor preta, tem-se a asserção completa: Amo SP: CIDADE LINDA. Sem grande elaboração estética e na esteira de repetir outros logos de cidades como I love $N Y$, a campanha é uma declaração de amor a SP o que ressalta o chamamento passional que justamente apoia-se nos investimentos figurativos e plásticos que sensibilizam afetando os humores. Difundido em tantas matérias que lhe dão cobertura mediática, o programa chega à população com um fazer saber que visa a sua adesão com participação efetiva. Tornar São Paulo cidade linda é, pois, uma convocação para todos se engajarem e advogarem por essa causa que é da municipalidade e da população.

Figura 16: O registro visual do logo que aparece em cada ação da zeladoria da gestão Dória.

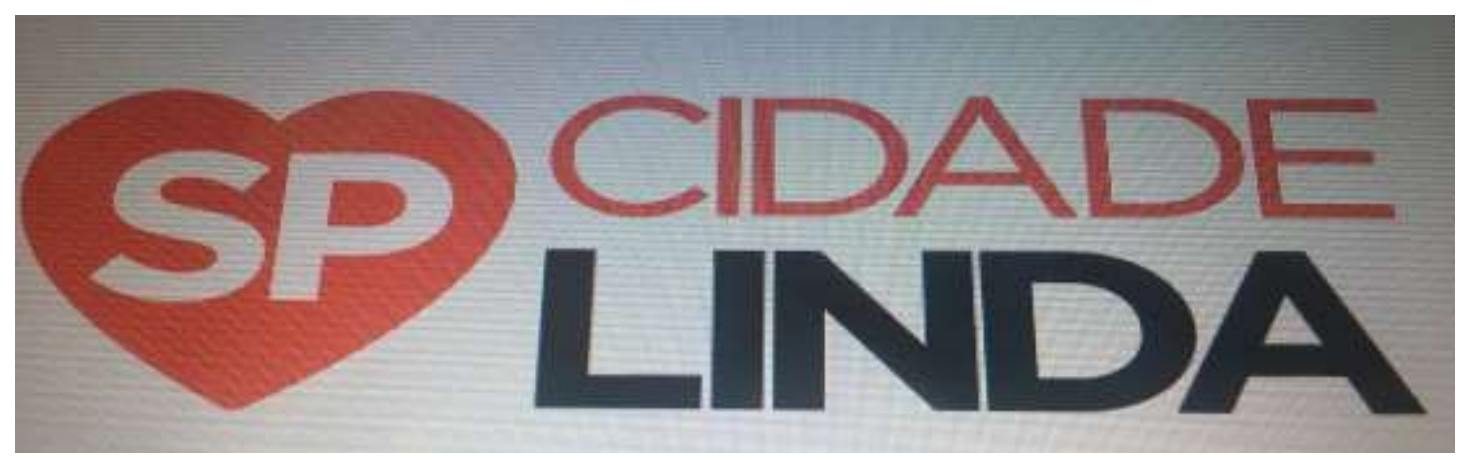

Fonte: Prefeitura do Município

Essas palavras de ordem vão ser encontradas no corpo a corpo das ações de zeladoria na cidade e com a sua população que pode só assistir ou entrar na ação 
colaborativa, o que é ainda mais instigado pela presença do prefeito que, sem excluir áreas da megalópole, aí se encontra, em suas palavras, trabalhando e socializando com todos.

Além disso, o fato de Dória vestir os uniformes de servidores, como o de gari, que tem nas costas o logo dessa campanha, empunhar escovão e estar de prontidão para as tarefas pegando transporte público nas primeiras horas do dia em pontos extremos das linhas de ônibus como faz qualquer trabalhador, configuram um conjunto de ações que não deixa de produzir efeitos de sentido de que esse prefeito trabalha como os paulistanos trabalhadores e quer estar próximos a eles para saber deles como está a cidade. Esse revestimento de busca de proximidade e de diálogo tem conferido efeitos de eficácia à presença do prefeito junto à população o que repercute na transformação de figura pública desconhecida poder tornar-se conhecida quer nos lugares do mutirão, quer nos noticiários que faz ver a força tarefa do fazer junto que é a estratégia maior de visibilidade. A cada ação de manutenção é colado nos postes um selo como se fosse o selo de qualidade, o carimbo de reconhecimento do fazer que lembra a todos nos postes de energia elétrica que lixo tem local adequado para ser descartado, um ato que está ao alcance de cada um para que esse continue cuidando da zeladoria.

Todavia, os embates do que é beleza na cidade por certo indicam que essa vai além de limpeza, conservação e apagar as manifestações parietais da pich/x/ação que foram listadas como as que tiram a beleza de São Paulo. A ação de apagamento do graffiti do corredor da Avenida 23 de maio substituído por jardins verticais e a de restauro dos arcos dos italianos ou arcos do Bixiga que nas suas cores de origem são agora monitorados dia e noite, para serem mantidos como patrimônio da história de São Paulo, só fizeram acirrar a polêmica com os pich/x/adores que, por mais de três décadas, clamam por seus direitos nos seus discursos, que estão interligando o trajeto diário de suas cidades dormitórios aos vários centros nos quais há oferta de trabalho. Em todo ir e vir das periferias aos centros a marcação das vozes dessa população está nas suas trilhas de desbravamento e conquista territorial que ela bravamente realiza e finca a sua bandeira paulistana, o pixo. Em alto brado essa população enfatiza que ela se encontra desassistida nas cidades dormitórios, má servida de transporte 
público, educação, serviços de saúde, habitação, lazer, entre tantos mais que denunciam e fazem ver os seus direitos de acesso.

Excluir o que por parâmetros de julgamento é classificado como a beleza do feio, sendo que essa manifestação conduz um clamor existencial de milhares de habitantes paulistanos, é uma ação possível? Como o poder público poderia outorgar-se esse papel sancionador de extermínio do pixo? O fato de as escrituras parietais da pixação continuarem no horizonte da cidade é uma resposta que essa visão de São Paulo assim plasmada é mesmo extraordinária e exige mais embates para ser sentida, ouvida e interpretada.

\section{O acelerar no contínuo transformar-se de São Paulo}

A narratividade e a ênfase nos enunciados de transformação continuada nos mostraram nos discursos analisados de São Paulo, que o visado é a manutenção do papel temático da urbe. As várias mutações da figuratividade em sua plástica-rítmica rearranjam o papel narrativo concentrado na liderança da cidade de modo a apresentá-la reatualizada na temporalidade do agora e na espacialidade do aqui. Esses rearranjos assinalam uma megalópole que para "fazer-se ser" persiste em sua trajetória do "fazer fazer" e do "fazer sentir". A sua dinamicidade fortemente reiterada é nosso ponto de vista de exterioridade que permitiu ver nos emblemas, slogans e ações os modos de permanência que montam a homogeneidade das configurações discursivas apenas com rearranjos figurativos. O dispositivo em que se apoia a visibilidade da identidade de São Paulo é, pois, explorado estrategicamente para produzir o efeito máximo de sua população diversa, manter-se consonante e fazendo junto o seu sentido de unidade de partes dispares.

Entranhados nos vários arranjos figurativo-plásticos, os modos de presença de São Paulo nos permitiram reconstruir os seus valores no papel temático que a cidade se destina seguir como horizonte de ação para ser em movimento, uma narrativa ainda com desdobramentos e sem ponto final.

O télos de São Paulo coloca como o seu papel temático o seu princípio de desenvolvimento. Fincado no fundo vermelho do escudo ou nas superdimensões territoriais da megalópole, esse mostra ser um transformar-se com a própria 
construção de si e de sua gente. Marcado pelas ações e atitudes de uma liderança, não são as metas e nem os fins que os conduzem, mas o sentido mesmo do télos que produz a disposição de São Paulo para mover-se e ser no tempo e espaço de sua gente.

\section{REFERÊNCIAS}

CHEN, Luciana et al. As escapatórias nas narrativas urbanas: Arcos do Bixiga como espaço de encenação de polêmicas. In: Anais - Colóquio Internacional Greimas: Desenvolvimentos, apropriações e desdobramentos para uma semiótica das práticas. São Paulo, PUC-SP, 2017, p. 751-767.

. Sentidos da visualidade urbana: o grafite nos Arcos do Bixiga. In:

OLIVEIRA, Ana Claudia de (Org.). Sentido e interação nas práticas: comunicação, consumo, educação e urbanidade. São Paulo: Estação da Letras e Cores, 2016, p. 378-379.

FLOCH, Jean-Marie. A contribuição da semiótica estrutural para o design de um hipermercado. Revista Galaxia. Trad. port. de Sílvia Alencar, com a colaboração de Jenara Miranda. Revisão de Ana Claudia de Oliveira e Yvana Fechine. São Paulo, Online n. 27, p. 21-47, jun. 2014. http://dx.doi.org/10.1590/1982-25542014119610.

Identité visuelle. Paris. P.U.F., 1990

. Petites mythologies de l'œil et de l'esprit. Pour une sémiotique plastique.

Amsterdan, Ed. Hadès-Benjamin,1985.

GREIMAS, Algirdas Julien. Da imperfeição. Trad. port. Ana Claudia de Oliveira, São Paulo, Estação das Letras e Cores e CPS Editora, 2017.

. Semiótica e Ciências Sociais. Trad. port. Álvaro Lorencini e Sandra Nitrini. São Paulo, Cultrix, 1981.

LANDOWSKI, Eric. A sociedade refletida. Ensaios de sociossemiótica I. Trad. port. Eduardo Brandão. São Paulo-Campinas, EDUC-Pontes, 1992.

. Interações arriscadas. Trad. port. Luiza Silva. São Paulo, Estação das Letras e Cores-CPS Editores, 2014.

. Passions sans non. Essays de sócio-sémiotique III. Paris, P.U.F., 2004.

. Presenças do outro. Ensaios de sociossemiótica II. Trad. port. Mary

Amazonas. São Paulo, Perspectiva, 2002.

INTERIN, v. 23, n. 1, jan./jun. 2018. ISSN: 1980-5276. 
OLIVEIRA, Ana Claudia de (Org.) São Paulo e Roma Práticas de vida e sentido. São Paulo, Estação das Letras e Cores-CPS Editores, 2017.

. (Org.). São Paulo: Público\&Privado. Abordagem sociossemiótica. São

Paulo, Ed. Estação das Letras e Cores, 2014.

Fotografia de fotopublicidade na ambientação urbana de São Paulo. Revista Significação n. 35. São Paulo, 2011, pp. 131-151.

. São Paulo, nos percursos de uma inteligência sensível?. In: SANTAELLA, Lucia (Org.) Cidades inteligentes. Para quem? Para que? 1 ed., São Paulo, Ed. Estação das Letras e Cores, v. 1, 2016, p. 146-175.

Interação e sentido nas práticas de vida. Revista Comunicação, mídia e consumo. São Paulo, 2014, v. 11, n. 31, pp. p.179-198.

PEZZINI, Isabella. Roma in divenire tra identità e conflitto. Roma, Nuova Cultura, 2017.

Recebido em: 02.10.2017

Aceito em: 04.11.2017 